\title{
Rudimentary Horn Pregnancy with Intrauterine Fetal Death
}

Laxmi R.C, Puspa Nagar, Madhuri Sribastava.

Dept of Obs/Gyn, Nepalguni Medical College, Kohalpur Banke, Nepal

\begin{abstract}
We present a 34 week by date but 21 weeks by USG intact rudimentary horn pregnancy with intra uterine fetal death, that is not communicating with uterus. In this case, initially, induction was done by PGE2 and Misoprostol, it failed; which is why laparotomy was done, revealing about 20 wks size globular mass $(20 \times 20 \times 16)$ attached on right side of the uterus. Right ovary and right Fallopian tube were normal, attached with the mass. Uterus, left ovary and left fallopian tube were normal.
\end{abstract}

Key words: Noncommunicating rudimentary horn, pregnancy, unicornuate uterus.

\section{Introduction}

Mauriceau reported first case of rudimentary horn pregnancy in 16691. Unicornuate uterus with rudimentary horn is a rare type of uterine malformation which is susceptible to many obstetrical complications, and in $80-90 \%$ cases of rudimentary horn, there is no communication between the two uterine cavities2. Incidence of pregnancy in such rudimentary horn cases is 1 in 76,0001. Conception in non-communicating rudimentary horn arises by trans-peritoneal migration of either spermatozoa or the fertilized ovum from the contralateral side3. Pregnancy outcome is poor, and the most dreaded complication is rupture of rudimentary horn pregnancy. In $80 \%$ of cases, the uterine rupture occurs in the first and second trimester; and in $20 \%$, in the third trimester1. Only $8 \%$ of rudimentary horn pregnancies are diagnosed before the symptoms appear.

\section{Case}

25 years old Primi from Salyan came to our Out Patient Department on $13^{\text {th }}$ Nov 2009 ( $27^{\text {th }}$ of Kartik 2066) with complaints of amenorrhoea for 8 months and absent fetal movements.

Patient was apparently all right 8 months back; she went to local health post when she missed her period, where pregnancy test was done was positive. She had two antenatal visits at two months and four months. First trimester was uneventful. By date it was 34 weeks of gestation.
On examination her general condition was good. No pallor, no icterus, no edema. Her vital sign were within normal limit.

Chest and cardiovascular system were normal. 0n abdominal examination, the height of uterus was 18 weeks size which was not corresponding to the period of amenorrhoea. Foetal part was palpable but there was no foetal heart sound. Per vaginal examination revealed eighteen weeks size mobile mass palpable. The cervical os was closed, cervix was uneffaced and tubular. Ultrasonography was done which showed gravid uterus with single dead fetus of 21 weeks. Cranial bones were over lapped, complete flexion of spine noted. Amniotic

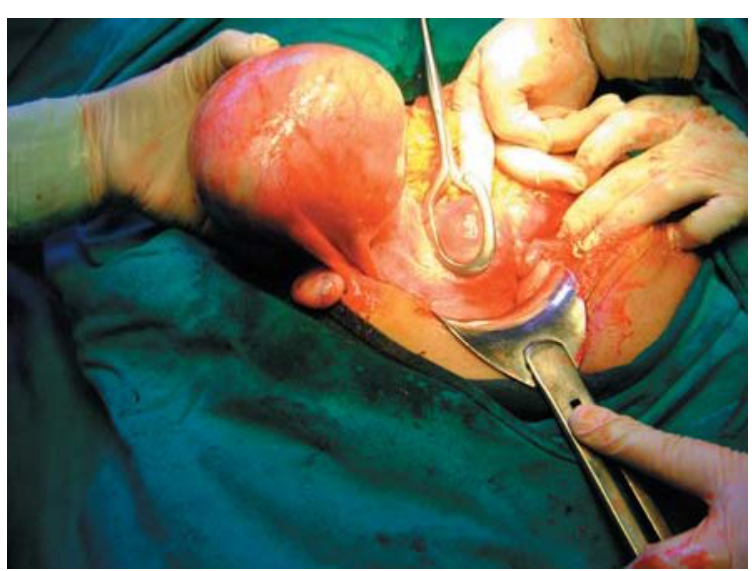

Fig1a. Fetus in right rudimentary horn. 


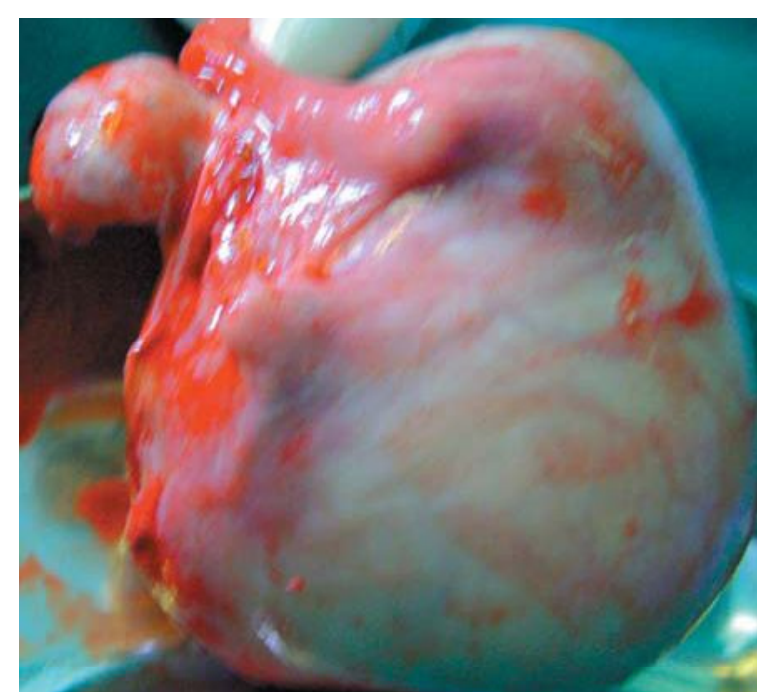

Fig1b. Fetus in right rudimentary horn.

fluid was nil. Placenta was posterior. She was admitted in labour room for induction in view of intrauterine fetal death. As all investigations were within normal limit, she was induced with 2 doses of PGE 8 hours apart followed by $200 \mathrm{ug}$ of misoprostol start and 400ug four hourly 4 doses (total $-1800 \mathrm{ug}$ ). As there was no uterine contraction, abdominal pregnancy was suspected and ultrasonography was repeated that showed single dead fetus enclosed within the membrane lying outside the uterus on the right side, within the broad ligament. With the diagnosis of pregnancy in right horn of bicornuate uterus, Laparotomy was done. Intraoperatively about 20 weeks size globular mass $(20 \times 20 \times 16)$ was seen attached on right side of the uterus. Right ovary and right Fallopian tube was normal which was attached with the mass. Uterus, left ovary and left fallopian tube were normal. Cut section revealed Single dead male fetus about 20 weeks size with placenta (fig 1) which was not communicating with uterus.

Her post operative period was uneventful; she was discharged on $8^{\text {th }}$ post operative day.

\section{Comments}

It is difficult to make the diagnosis of rudimentary horn pregnancy before it ruptures or surgical exploration. However trans-vaginal ultrasonography has been successful in detecting such anomaly where laparoscopic management has been carried out ${ }^{5-}$ 7. Implantation in the rudimentary hemi uterus is associated has been associated with intra uterine fetal demise, similar to our case. ${ }^{8}$

More liberal use of high-resolution sonography and MR imaging in doubtful cases may assist in an earlier diagnosis of rudimentary horn pregnancy making better surgical or medical therapy possible ${ }^{9,10}$.

In conclusion, reassessment of the case topped up with repeat ultrasound for a non-responsive uterus to

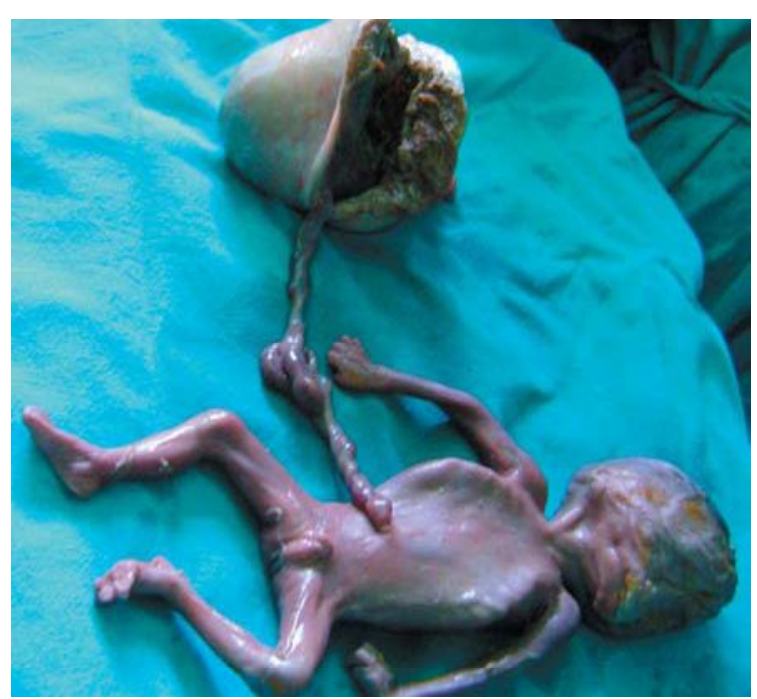

Fig2. Cut section of rudimentary horn showing a male fetus.

prostaglandin supplemented by laparotomy proved non-fatal and rewarding.

\section{References}

1. Nahum GG. Rudiementary uterine horn pregnancy: the $20^{\text {th }}$ century worldwide experience of 588 cases. J. Reprod Med 2002; 47: 151-63.

2. Liu MM. Unicornuate uterus with rudimentary horn. Int. J Gynecol Obstet 1994; 44: 149-53.

3. O'Leary JL, O'Leary JA. Rudimentary horn pregnancy. Obstet Gynecol 1963; 22:371-5.

4. Jayasinghe Y, Rane A, Stalewksi H, Grover $\mathrm{S}$. The presentation and early diagnosis of the rudimentary uterine horn. Obstet Gynecol 2005; 105: 1456-67.

5. Holden R, Hart P. First trimester Rudimentary horn

6. pregnancy: Pre rupture USG. Obst Gynae 1983; 61:56

7. Chopra S, Suri V, Aggarwal N. Rudimentary horn

8. pregnancy: prerupture diagnosis and management. Indian J Med Sci 2007; 61(1):28-9.

9. Yahata T, Kurabanyashi Tueder. Tubal laparoscopic management of rudimentary horn pregnancy (a case report). Reprod. Medicine 1898 42(3) $223-6$

10. Reichman D, Laufer MR, Robinson BK: Pregnancy outcomes in unicornuate uteri: a review. Fertil Steril 91(5): 1886, 2009

11. Edelman AB, Jensen JT, Lee DM, et al: Successful medical abortion of a pregnancy within a noncommunicating rudimentary uterine horn. Am J Obstet Gynecol 189:886, 2003

12. Worley KC, Hnat MD, Cunningham FG: Advanced extrauterine pregnancy: Diagnostic and therapeutic challenges. Am J Obster Gynecol 198:287. el, 2008 